\title{
Dairy product consumption and risk of hip fracture: a systematic review and meta- analysis
}

Shanshan Bian ${ }^{1 \dagger}$, Jingmin $\mathrm{Hu}^{1 \dagger}$, Kai Zhang ${ }^{1}$, Yunguo Wang ${ }^{2}$, Miaohui $\mathrm{Yu}^{3}$ and Jie $\mathrm{Ma}^{3^{*}}$

\begin{abstract}
Background: Dairy product consumption may affect the risk of hip fracture, but previous studies have reported inconsistent findings. The primary aim of our meta-analysis was to examine and quantify the potential association of dairy product consumption with risk of hip fracture.
\end{abstract}

Methods: We searched the databases of PubMed and EMBASE for relevant articles from their inception through April 17, 2017. The final analysis included 10 cohort studies and 8 case-control studies. Random-effects models were used to estimate the pooled risk. Subgroup and dose-response analyses were conducted to explore the relationships between the consumption of milk and the risk of hip fracture.

Results: After pooling the data from the included studies, the summary relative risk (RR) for hip fracture for highest versus lowest consumption were 0.91 (95\% Cl: 0.74-1.12), 0.75 (95\% Cl: 0.66-0.86), 0.68 (95\% Cl: 0.61-0. 77), 1.02 (95\% Cl: 0.93-1.12) for milk, yogurt, cheese, and total dairy products in cohort studies, respectively. Higher milk consumption [Odds ratio (OR), $0.71,95 \% \mathrm{Cl}: 0.55-0.91]$ was associated with lower risk of hip fracture for highest versus lowest consumption in case-control studies. After quantifying the specific dose of milk, the summary RR/OR for an increased milk consumption of $200 \mathrm{~g} /$ day was 1.00 (95\% Cl: 0.94-1.07), and 0.89 (95\%Cl: 0.64-1.24) with significant heterogeneity for cohort and case-control studies, respectively; There was a nonlinear association between milk consumption and hip fracture risk in cohort, and case-control studies.

Conclusions: Our findings indicate that consumption of yogurt and cheese was associated with lower risk of hip fracture in cohort studies. However, the consumption of total dairy products and cream was not significantly associated with the risk of hip fracture. There was insufficient evidence to deduce the association between milk consumption and risk of hip fracture. A lower threshold of $200 \mathrm{~g} /$ day milk intake may have beneficial effects, whereas the effects of a higher threshold of milk intake are unclear.

Keywords: Hip fracture, Diet, Dairy products, Milk consumption, Meta-analysis, Case-control study, Cohort study

\section{Background}

Hip fracture is the most serious type of osteoporotic fracture. Hip fractures can lead to other comorbidities, increased mortality risk, and enormous social and economic costs [1]. According to recent reports, approximately 1.66 million patients are diagnosed with hip fracture occur each year worldwide [2, 3]. World population surveys have shown that the number of adults older

\footnotetext{
* Correspondence: majie_tjykdxdeyy@126.com

${ }^{\dagger}$ Equal contributors

${ }^{3}$ Health Examination Centre, the Second Hospital of Tianjin Medical

University, No. 23 Pingjiang Road, Tianjin 300211, China

Full list of author information is available at the end of the article
}

than 60 years old was 841 million in 2013, which is approximately four times as high as that in 1950 (202 million) [4]. The incidence of hip fracture increases linearly with age [5]. The pathogenesis of hip fracture is multifactorial. The main factors contributing to the development of hip fracture are bone mineral density, falls, and lifestyle habits. Lifestyle habits include calcium intake, general nutrition, and exposure to sunlight, physical activity, smoking, and alcohol intake [6-10]. It is known that nutrition, especially dairy product consumption, has an important effect on maintaining bone health. 
Dairy products have been hypothesized to help prevent hip fracture because they are a significant source of calcium, proteins, and other bioactive nutrients beneficial for bone health [11]. However, the effects of dairy products on hip fractures have not been established. The benefit of milk, as a main dietary source of calcium in reducing hip fracture risk has yet to be debated. More recently, a study by Sahni et al., [12] indicated that there was a nonsignificant $42 \%$ reduction in hip fracture risk in elderly adults who consumed more than 7 milk servings per week, compared with those who consumed less than one serving per week in the Framingham Original Cohort. Michaëlsson et al., [13] found that for every glass of milk consumed per day, women had a significant 9\% increase in hip fracture risk, although no association was observed in men. Meanwhile, the data suggested that higher cheese or yogurt intake may reduce hip fracture risk in both men and women [7].

Two previous meta-analyses have been published with results focused only on milk consumption [14, 15]. However, some studies assessed the association between hip fracture and consumption of different types of dairy products, since different types of products contain varying nutrient contents (e.g., milk is rich in lactose, cheese and yogurt can provide lactic acid bacteria). Choosing dairy products like milk, cheese, or yogurt instead of cream can decrease fat, and cholesterol. Therefore, it is important to evaluate the influence of the consumption of different types of dairy products (total dairy products, milk, yogurt, cheese, and cream) on hip fracture risk.

\section{Methods}

\section{Search strategy}

The primary aim of our meta-analysis was to examine and quantify the potential association of dairy product consumption with risk of hip fracture. Searches were performed on PubMed and EMBASE databases from their inception to April 17, 2017. The search terms used were as follows: "hip fracture" (or "subtrochanteric fracture" or "trochanteric fracture" or "intertrochanteric fracture" or "femoral neck fracture") and "dairy products" (or "milk" or "cheese" or "yogurt" or "cream"). No language restrictions were applied in the search strategy. An additional article [16] was identified through the bibliographies of relevant reviews. Figure 1 and Additional file 1 provides detailed search terms and search strategies for both databases.

\section{Eligibility criteria}

To identify eligible studies, two independent investigators (S.B.and J.H.) performed an initial screening of all titles and abstracts, and then assessed the full text of all relevant studies in detail. Articles were included in this meta-analysis if they met the following criteria: (1) cohort or case-control study design; (2) studies that evaluated and clearly defined exposure to total dairy products, milk, cheese, yogurt, or cream; (3) studies with the risk of hip fracture as the outcome of interest; and (4) studies reporting odds ratio (OR) or relative risk (RR) with 95\% confidence intervals (CI) for the association between dairy product exposure and risk of hip fracture. Studies had to define hip fracture using the criteria based on the International Classification of Diseases, 10th revision (ICD-10) or medical records. If there were multiple publications from the same study, we selected the most recent study for the meta-analysis. Studies were excluded if they provided insufficient data, such as letters, reviews, comments, or animal studies. Two previous meta-analyses had been published with results focused only on milk consumption. The meta-analysis conducted by Bischoff-Ferrari et al., [14] was excluded, because the report contained duplicated data. The metaanalysis conducted by Kanis et al., [15] was included in our meta-analysis. The flow diagrams of the selection process and results are shown in Fig. 1.

\section{Data processing and quality assessment}

Two authors (Y.W. and K.Z.) independently extracted the following information from each included study: author name, research region, publication year, study design, study name, subjects (number of cases), sex, mean/ median age of the study individuals, duration of followup for cohort studies, exposure and quantity of intake, dietary assessment method, the maximally adjusted risk estimates with 95\% CI for the highest versus the lowest category of consumption, and adjustment for confounders in analyses.

In the dose-response meta-analysis of the relationship between dairy products and hip fracture risk, the number of cases and participants or person-years, the mean or median dairy product consumption for each exposure category, and the RR/OR and its variance estimate for three or more quantitative exposure categories were compiled from the included studies. The median level of milk consumption (g/day) for each exposure category was presented with the relevant RR/OR and corresponding 95\% CI. We used standard conversions from the Food Standards Agency to convert glasses/d to g/d (1 glass $=200 \mathrm{~mL}$ ) for relevant studies $[17,18]$. Assumptions were used to convert $\mathrm{ml} / \mathrm{d}$ to approximate $\mathrm{g} / \mathrm{d}$ [19]. If dairy products were reported as servings, drinks, or times per day/week/month instead of quantity, the following average amounts were used to represent a serving: $177 \mathrm{~g}$ for total dairy products, $244 \mathrm{~g}$ for milk and yogurt, and $43 \mathrm{~g}$ for cheese consumption [20,21].

Two investigators (M.Y. and K.Z.) independently assessed the quality of the 17 included studies (Excluding the meta-analysis [15] as previously mentioned) 


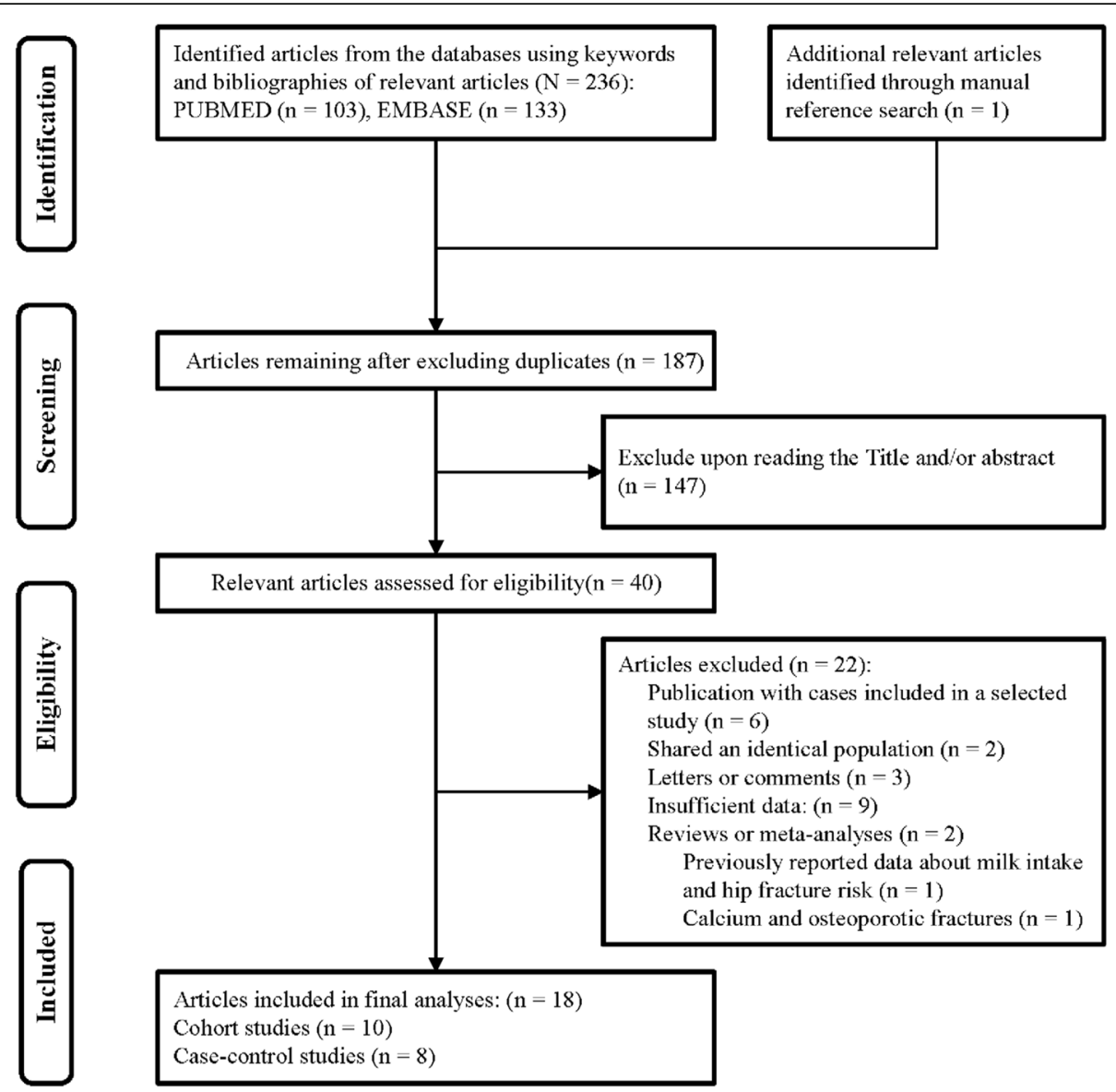

Fig. 1 Search strategy and selection of studies for this meta-analysis

using the Newcastle-Ottawa scale (NOS) [22]. This scale scores studies on three categories (selection, comparability of study groups, and the outcome of interest). A study can be awarded a maximal score of 9 , which represents the highest quality study.

\section{Statistical analysis}

Effect sizes were estimated with RR in cohort studies and OR in case-control studies. Cohort and case-control studies were pooled separately in our meta-analysis. We quantified the association of dairy product consumption with hip fracture risk using random-effects models [23].

Subgroup and meta-regression analyses were performed to assess potential sources of heterogeneity stratified by some of the baseline characteristics, such as study quality, region, sex, number of cases, duration of follow-up for cohort studies, age, and adjustment for potential confounders. We also investigated the influence of different types of dairy product consumption, including total dairy products, yogurt, cheese, and cream.

In the dose-response meta-analysis, we used the method proposed by Greenland and Longnecker [24] to estimate the dose-response trend of the relationship between dairy product consumption and hip fracture risk. We applied random effects models [25] to estimate the summary RR or OR within each study.

Between-study heterogeneity was evaluated using both the $\mathrm{Q}$ and $\mathrm{I}^{2}$ statistics. A Q statistic with $P<0.10$ indicated heterogeneity, whereas $\mathrm{I}^{2}$ values of $0 \%, 25 \%, 50 \%$, and $75 \%$ represented no, low, moderate, and high heterogeneity, respectively [25]. Publication bias was considered by visual inspection of the contour-enhanced funnel plot symmetry as well as by Egger's test [26] and Begg's test [27]. Furthermore, Duval's non-parametric trim-and-fill procedure was performed to adjust for the number of missing studies and estimate possible publication bias [28]. Meta-analyses were conducted with R version 3.1.2 (The R Foundation for Statistical Computing, Vienna, Austria), using the following packages: meta, foreign, dosresmeta, Hmisc, survival, SparseM, and rms. All statistical tests were two-sided, and $P$ values $<0.05$ indicated statistical significance.

\section{Results}

Literature search

Figure 1 shows the search strategy and selection of studies for our meta-analysis on dairy product consumption 
and the risk of hip fracture. We identified one additional article by manually searching the reference lists from the included studies [16]. A total of 18 articles [12, 13, 15, $16,29-42]$ were included in the present meta-analysis (Additional file 2).

\section{Characteristics of included studies}

Table 1 shows the detailed baseline characteristics of the included studies. A total of 18 observational studies (10 cohort studies $[12,13,15,16,33-37,42]$ and 8 casecontrol studies [29-32, 38-41]) involving 381,987 participants were included in the final analysis. The 10 cohort studies were published between 1997 and 2014, with a total of 8613 hip fracture events, and 363,557 participants. The length of follow-up ranged from 3 to 22 years. Eight cohort studies included both sexes. One cohort study included only male individuals and the remaining cohort study recruited only females. Four cohort studies were conducted in the USA, 4 were conducted in Europe, 1 was conducted in Asia, and 1 was a meta-analysis of a multicenter study including participants from Europe, Australia, and Canada. The 8 case-control studies were published between 1992 and 2010, and included 3815 hip fracture cases and 6415 controls. Geographic regions of the case-control studies included Europe $(n=3)$, Australia $(n=1)$, USA $(n=1)$, and Asia $(n=3)$.

\section{Milk consumption and risk of hip fracture}

Nine cohort studies [12, 13, 15, 16, 33, 34, 36, 37, 42] and 7 case-control studies [29-32, 38, 39, 41] reported the association between milk consumption and risk of hip fracture.

\section{Meta-analysis of cohort studies}

For cohort studies, the pooled RR for highest versus lowest category of milk consumption and hip fracture risk was 0.91 (95\% CI: 0.74-1.12, $\mathrm{I}^{2}=75.0 \%$, $\mathrm{P}_{\text {heterogeneity }}$ $<0.01$ ) (Fig. 2a), indicating that milk consumption had no association with hip fracture risk. The analyses producing the pooled estimates indicated heterogeneity.

The contour-enhanced funnel plot demonstrated asymmetry (Fig. 3a). However, Egger's test $(P=0.81)$ and Begg's test $(P=0.30)$ indicated no publication bias with regard to milk intake and hip fracture risk. We used the trim-and-fill method to confirm robustness of the results. There were no significant changes to the results after using the trim-and-fill method when including four missing articles (adjusted random effects summary RR: 1.06, 95\% CI: 0.91-1.23).

\section{Meta-analysis of case-control studies}

The case-control studies indicated that participants in the highest categories of milk consumption had a $29 \%$ reduction in the risk of hip fracture $(\mathrm{OR}=0.71,95 \% \mathrm{CI}$ :
$0.55-0.91, \mathrm{I}^{2}=54 \%, \mathrm{P}_{\text {heterogeneity }}=0.04$ ) (Fig. 2b). Pooled estimate analyses indicated heterogeneity.

For case-control studies, the contour-enhanced funnel plot showed asymmetry (Fig. 3b). There were no significant changes to the results after using the trim-and-fill method when including one missing article (adjusted random effects summary OR: 0.74, 95\% CI: 0.57-0.97). The trim-and-fill estimates should be interpreted with great caution due to the limitations inherent to the methods used.

\section{Quality study, subgroup, and meta-regression analyses}

The quality of the 17 included studies (Excluding the meta-analysis study [15] as discussed previously) using the Newcastle-Ottawa scale (NOS) [22] is shown in Tables 2 , and 3.th $=$ tlb $=$ th $=$ tlb $=$

In subgroup and meta-regression analyses, the null association between milk consumption and hip fracture risk was consistently observed in the subgroup analysis of 9 cohort studies [12, 13, 15, 16, 33, 34, 36, 37, 42] stratified by different factors (Table 4), except for studies that did not adjust for total energy intake. In addition, there was an inverse association between calcium and vitamin D supplements and hip fracture risk in cohort studies. An inverse association between milk consumption and hip fracture risk was consistently observed in case-control studies (Fig. 2b); subgroup analysis showed that milk consumption had no association with hip fracture risk in studies from the USA.

\section{Dose-response analysis}

The relationship between milk consumption and hip fracture risk was further quantified via dose-response analysis for milk consumption. The summary RR for an increased milk consumption of $200 \mathrm{~g} /$ day was 1.00 (95\% CI: 0.94-1.07), with significant heterogeneity among cohort studies $\left(\mathrm{I}^{2}=87 \%, \mathrm{P}_{\text {heterogeneity }}<0.01\right.$, Fig. 4). The dose-response associations between milk consumption and risk of hip fracture in the cohort studies $(n=7)$ $[12,13,16,33,34,37,42]$ are shown in Fig. 5a. There was a nonlinear positive association between milk consumption and hip fracture risk $\left(\mathrm{P}_{\text {nonlinerity }}<0.01\right)$, with a rapid increase in risk when milk consumption increased from 0 to $600 \mathrm{~g} / \mathrm{d}$; there was no further increase in risk with milk consumption between 600 and $1200 \mathrm{~g} / \mathrm{d}$.

The summary OR for increasing milk consumption by 200 g/day was 0.89 (95\% CI: 0.64-1.24), with significant heterogeneity among case-control studies $\left(\mathrm{I}^{2}=68 \%\right.$, $\mathrm{P}_{\text {heter- }}$ ogeneity $=0.05$, Fig. 4). Dose-response meta-analysis of the association between milk consumption and hip fracture risk in case-control studies $(n=3)[30,39,41]$ suggested a nonlinear association between milk consumption and hip fracture risk $\left(\mathrm{P}_{\text {nonlinerity }}=0.28\right)$, with a reduction in risk 


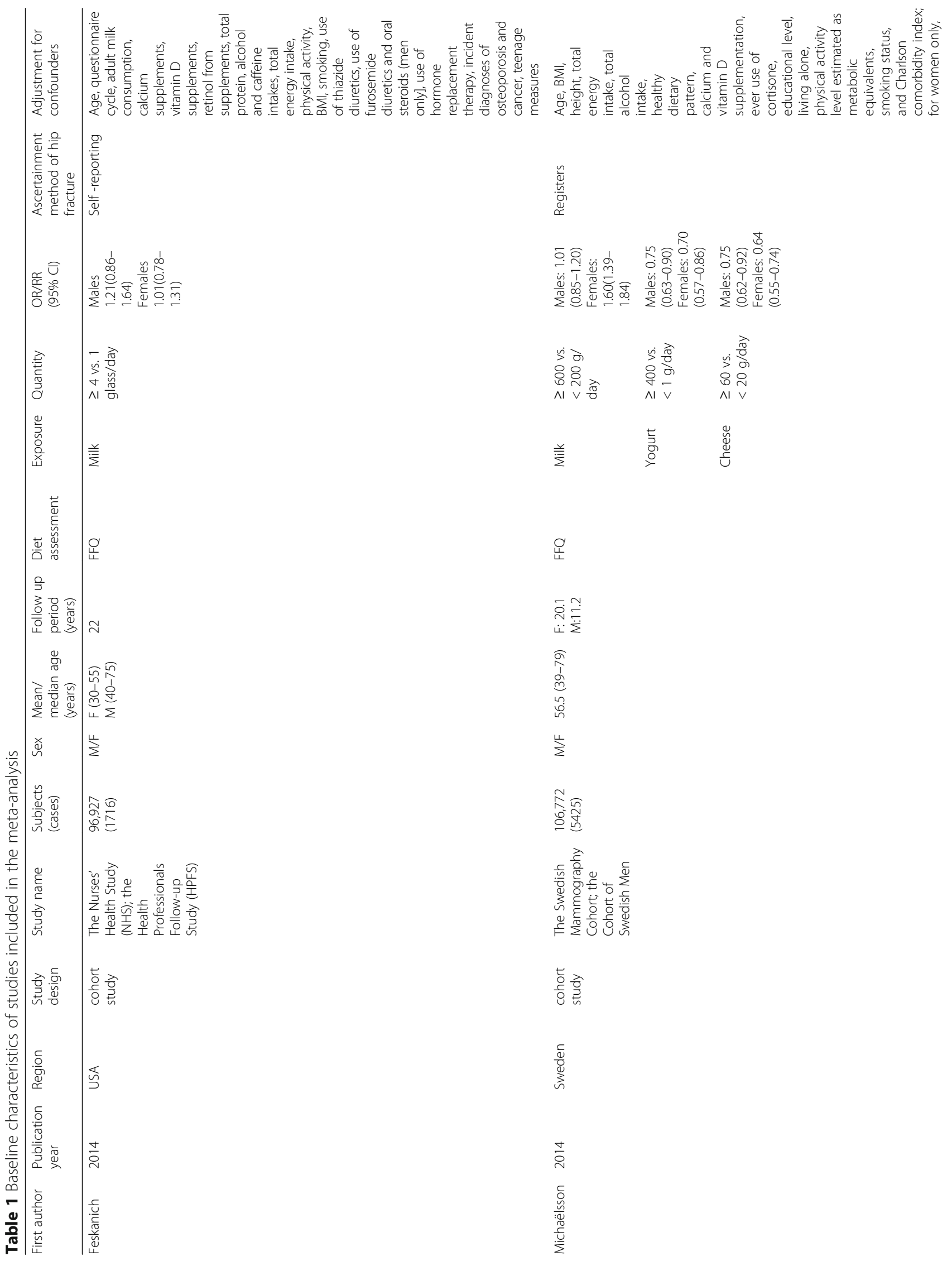




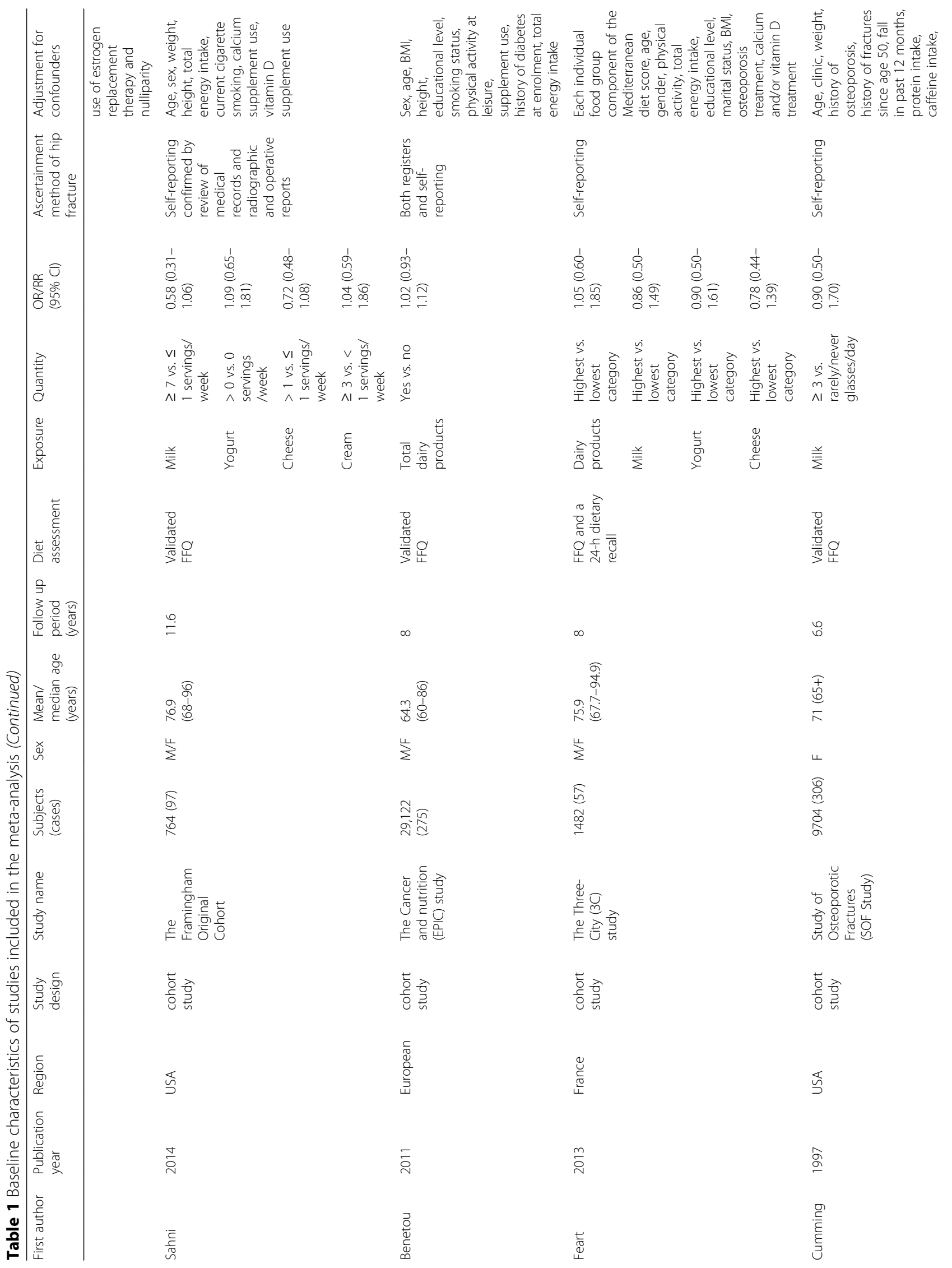




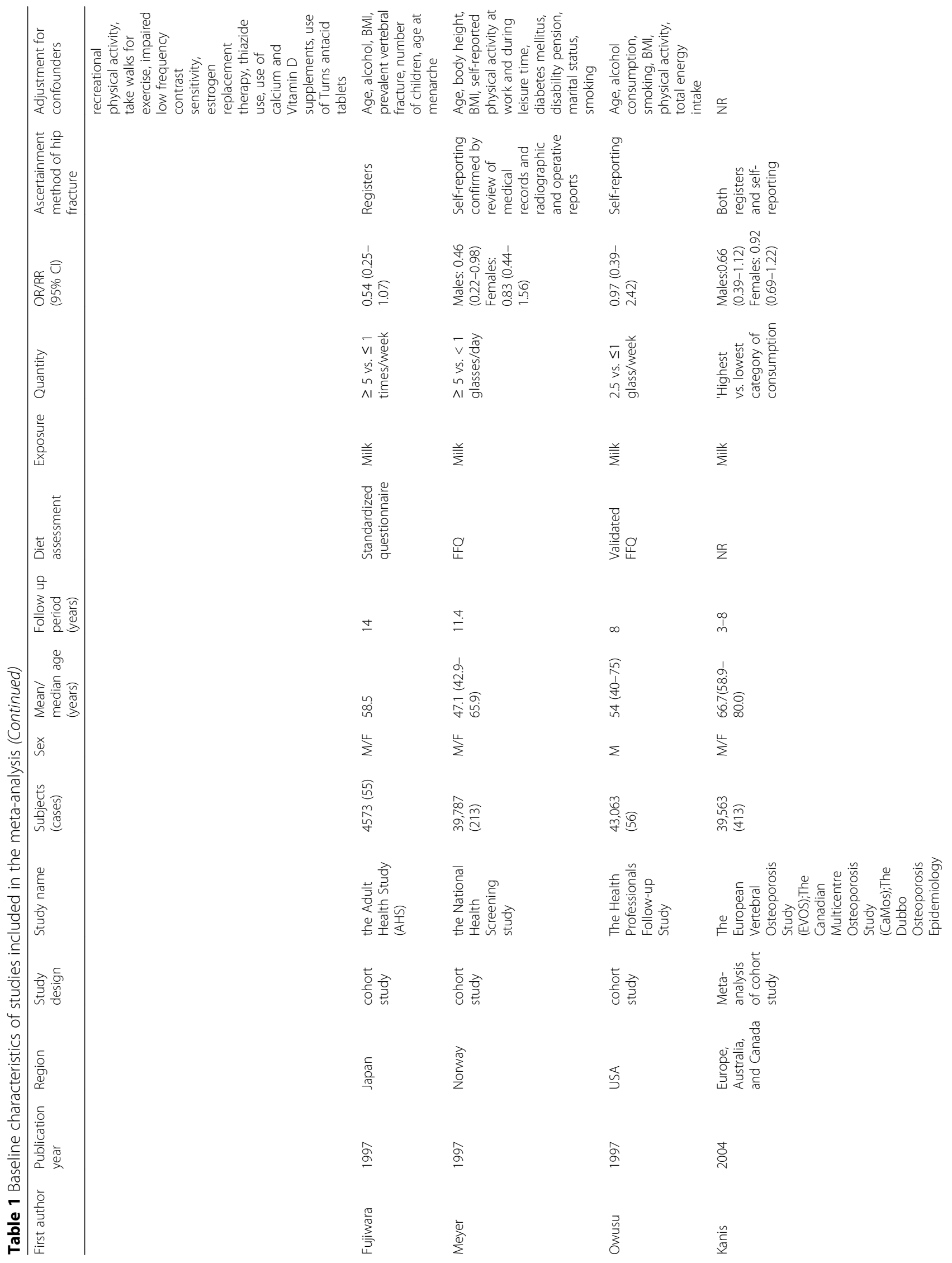




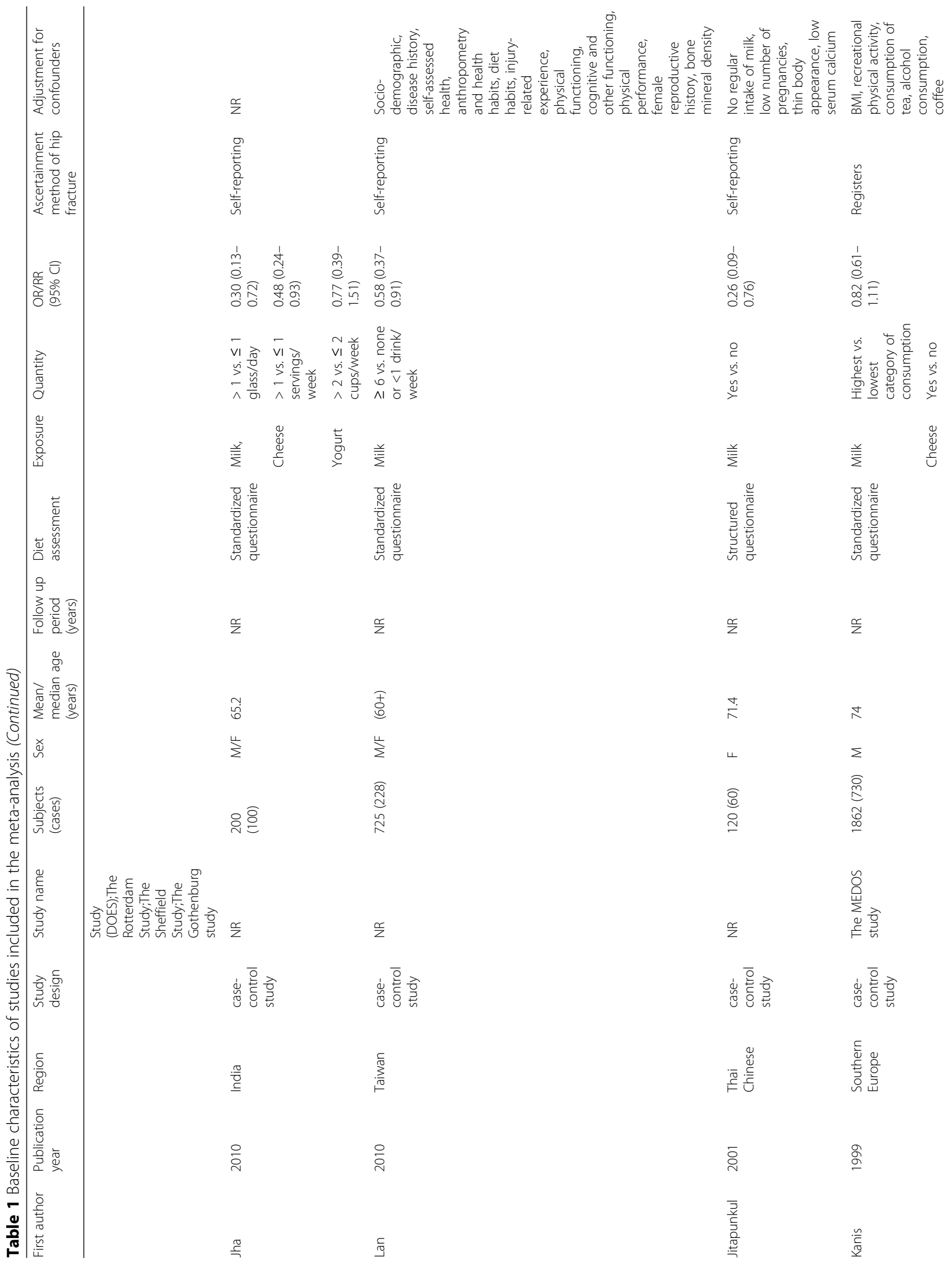


Bian et al. BMC Public Health (2018) 18:165

Page 9 of 16

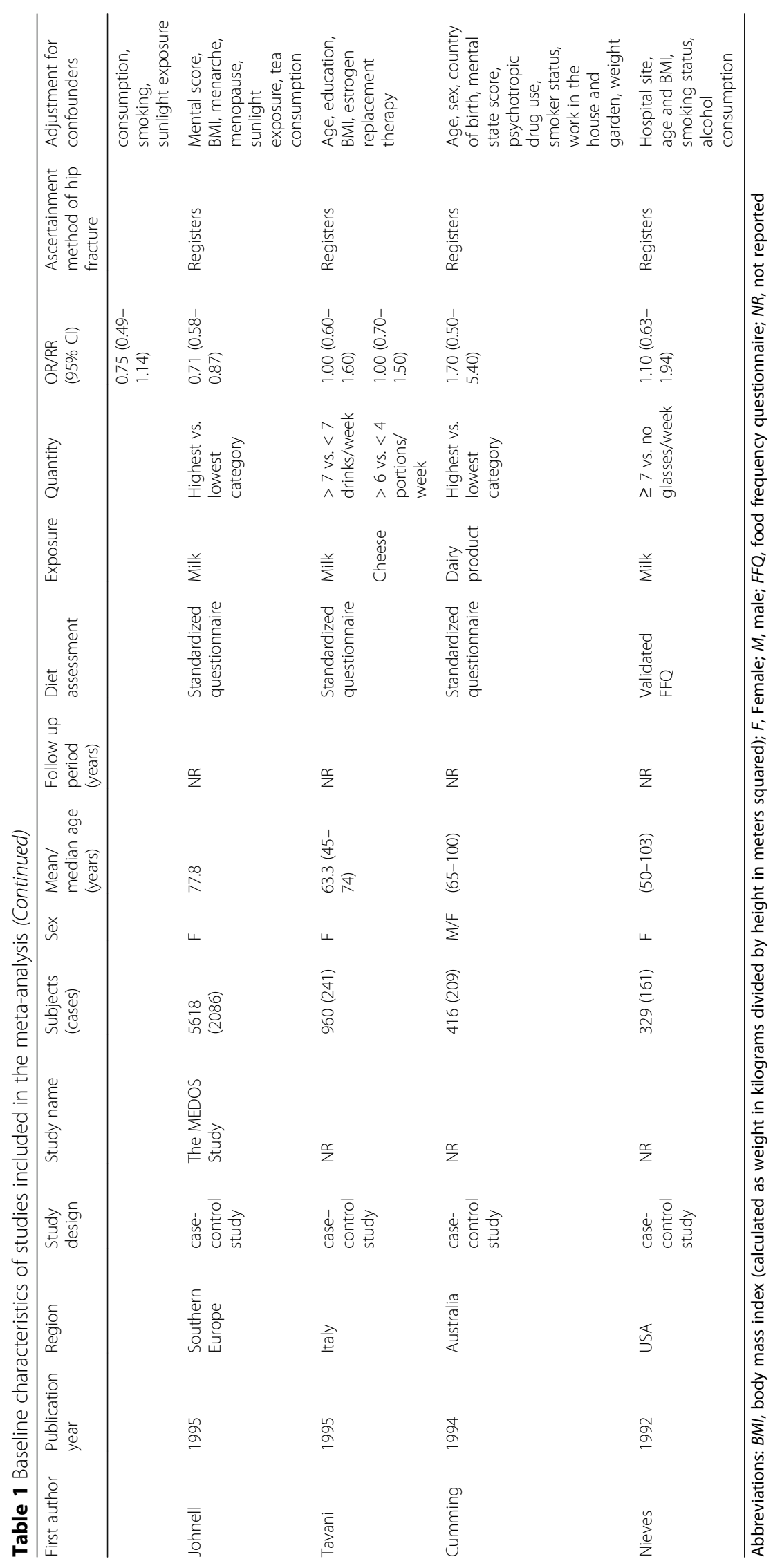




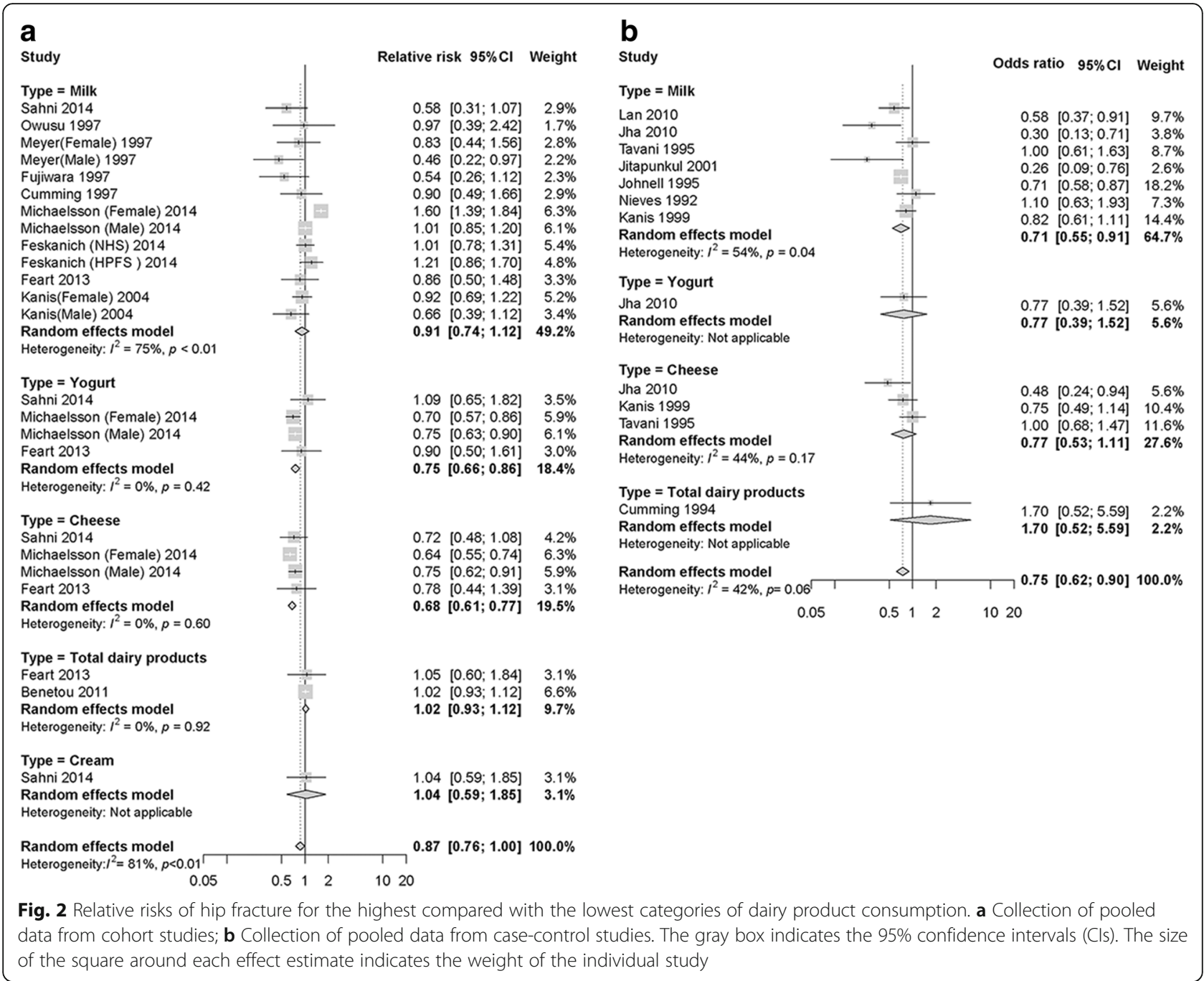

with milk consumption of 200-600 g/d. However, the confidence intervals were wide for all outcomes (Fig. 5b).

\section{Other dairy product intake and hip fracture risk}

Consumption of yogurt $(n=3)$ and cheese $(n=3)$ reduced hip fracture risk, total dairy products $(n=2)$ and cream $(n$ $=1$ ) showed no association with hip fracture risk in cohort studies for the highest versus lowest category (Fig. 2a). Consumption of total dairy products $(n=1)$, yogurt $(n=$ $1)$, and cheese $(n=3)$ in case-control studies showed no association with hip fracture risk (Fig. 2b). No additional contour-enhanced funnel plots, subgroup, or doseresponse analyses for total dairy products, yogurt, cheese, and cream could be performed because of the limited results reported in the included studies.

\section{Discussion}

In this meta-analysis, a higher intake of yogurt and cheese was associated with a significant reduction in hip fracture risk as compared to low intake in cohort studies, and there was no overall association reported in case-control studies. Cohort and case-control studies reported no overall associations between total dairy products and cream, and hip fracture risk. Milk consumption was associated with a non-significant 9\% lower hip fracture risk for highest versus lowest consumption in cohort studies. Nevertheless, the results of the case-control studies showed a significant $29 \%$ reduction in hip fracture risk for highest versus lowest consumption. The association between milk consumption and hip fracture risk remained unchanged when stratified by multiple study characteristics. Our finding for highest versus lowest milk consumption is consistent with the results from previous meta-analyses [14, 15]. Highest versus lowest analysis is limited, owing to differences in both the level, and range of milk consumption between the included studies, which may contribute to heterogeneity in the results. However, we further refined the precision of the risk estimates by applying the dose-response analysis for milk consumption, which may be important to guide recommendations for milk consumption with regard to risk 


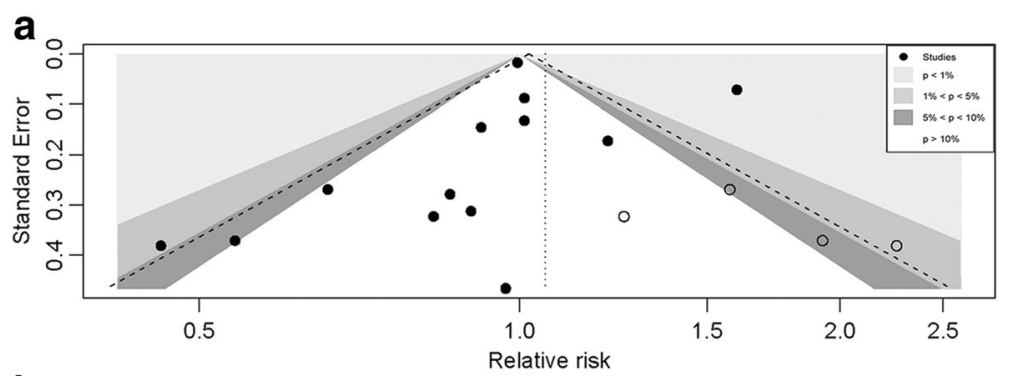

b

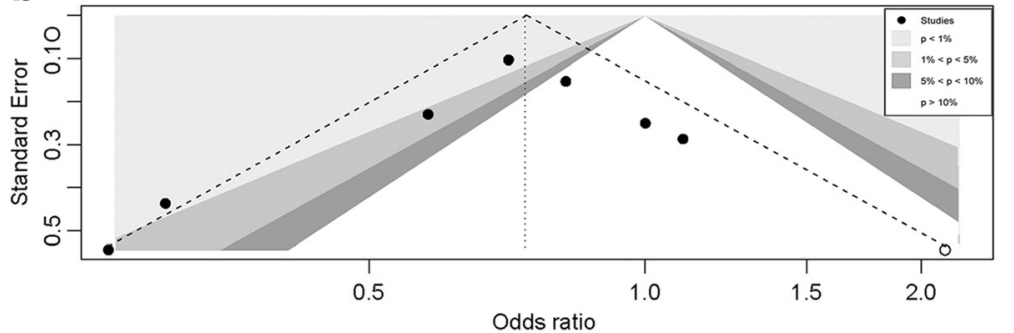

Fig. 3 Contour-enhanced funnel plot of Milk consumption and hip fracture risk. a Data are collected from cohort studies; b Collection of data from case-control studies. Each dot indicates a different study

reduction. Meanwhile, it is important to define and evaluate the potential threshold effects between milk consumption and hip fracture risk. In the nonlinear dose-response analysis, a low threshold of 200 g/day may have beneficial effects, whereas there is a degree of uncertainty with higher milk consumption.

Dairy products have a complicated influence on human health, and evidence on the impact of dairy products on hip fracture development remains inconsistent. Some previous studies indicated that dairy products might be beneficial for the prevention of hip fracture, as they contain calcium and vitamin D. Dairy products are often fortified with vitamin D in the United States, which is essential for the absorption of calcium and bone health [43]. A previous study has shown that vitamin D supplementation, with or without calcium, may have only minor effects on fracture risk among communitydwelling individuals [44]. Nonetheless, Chapuy et al., [45] showed that hip fracture risk was reduced with vitamin D and calcium supplementation among elderly women (mean age 84 years) who had very low vitamin D levels, with concurrent low dietary intake of calcium.

Table 2 Quality assessment of the included cohort studies

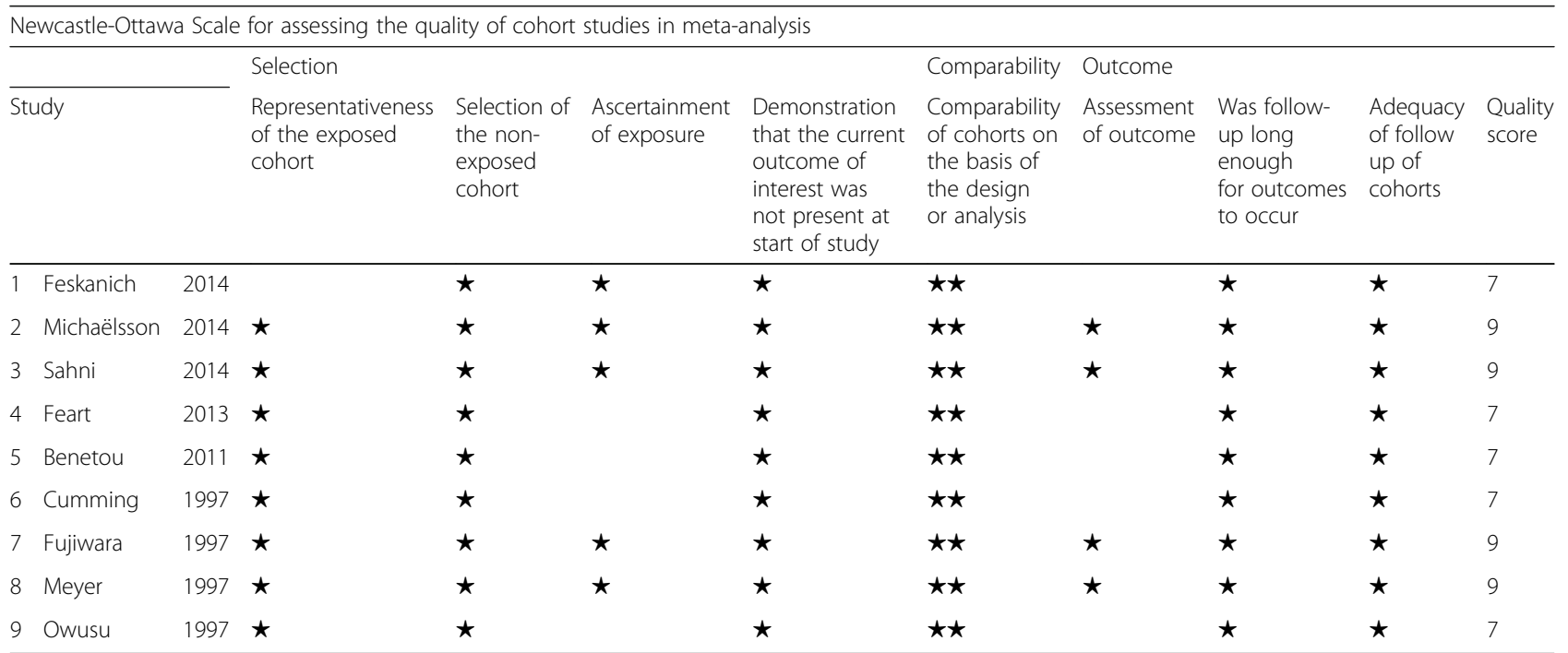

A study can be awarded a maximum of one star for each numbered item within the Selection and Outcome categories. A maximum of two stars can be given for Comparability 
Table 3 Quality assessment of the included case-control studies

\begin{tabular}{|c|c|c|c|c|c|c|c|c|c|c|}
\hline \multicolumn{11}{|c|}{ Newcastle-Ottawa Scale for assessing the quality of case control studies in meta-analysis } \\
\hline & & Selection & & & & Comparability & Outcome & & & \\
\hline \multicolumn{2}{|l|}{ Study } & $\begin{array}{l}\text { Is the case } \\
\text { definition } \\
\text { adequate }\end{array}$ & $\begin{array}{l}\text { Representativeness } \\
\text { of the cases }\end{array}$ & $\begin{array}{l}\text { Selection } \\
\text { of controls }\end{array}$ & $\begin{array}{l}\text { Definition } \\
\text { of controls }\end{array}$ & $\begin{array}{l}\text { Comparability } \\
\text { of cases and } \\
\text { controls on the } \\
\text { basis of the } \\
\text { design or analysis }\end{array}$ & $\begin{array}{l}\text { Ascertainment } \\
\text { of exposure }\end{array}$ & $\begin{array}{l}\text { Same method } \\
\text { of ascertainment } \\
\text { for cases and } \\
\text { controls }\end{array}$ & $\begin{array}{l}\text { Non- } \\
\text { Response } \\
\text { rate }\end{array}$ & $\begin{array}{l}\text { Quality } \\
\text { score }\end{array}$ \\
\hline 1 Jha & 2010 & & & & $\star$ & $\star \star$ & & $\star$ & $\star$ & 5 \\
\hline 2 Lan & 2010 & & & & $\star$ & $\star \star$ & & $\star$ & & 4 \\
\hline 3 Jitapunkul & 2001 & & $\star$ & & $\star$ & $\star \star$ & & $\star$ & & 5 \\
\hline 4 Kanis & 1999 & $\star$ & $\star$ & & $\star$ & $\star \star$ & $\star$ & $\star$ & $\star$ & 8 \\
\hline 5 Johnell & 1995 & $\star$ & $\star$ & & $\star$ & $\star \star$ & $\star$ & $\star$ & $\star$ & 8 \\
\hline 6 Tavani & 1995 & $\star$ & $\star$ & & $\star$ & $\star \star$ & $\star$ & $\star$ & $\star$ & 8 \\
\hline 7 Cumming & 1994 & $\star$ & $\star$ & $\star$ & $\star$ & $\star \star$ & $\star$ & $\star$ & & 8 \\
\hline 8 Nieves & 1992 & $\star$ & $\star$ & & $\star$ & $\star \star$ & $\star$ & $\star$ & $\star$ & 8 \\
\hline
\end{tabular}

A study can be awarded a maximum of one star for each numbered item within the Selection and Outcome categories. A maximum of two stars can be given for Comparability

Supplementation with vitamin D and calcium is a health-seeking behavior, which could be an important confounder.

Other studies argue that D-galactose in milk might promote oxidative stress and inflammation, which in turn influences the risk of fracture and mortality [13]. $\mathrm{D}$-galactose is known to cause oxidative stress, aging, and inflammation. Milk contains high levels of lactose and galactose, while cheese and yogurt contain lower or non-existent levels. Previous cohort studies observed that milk consumption had a positive relationship with concentrations of marks for oxidative stress and inflammation.

These data suggest that higher milk, yogurt, and cheese consumption may contribute to a lower hip fracture risk, although the results with respect to milk consumption were not statistically significant in cohort studies. In contrast to high milk consumption, high yogurt and cheese consumption was associated with a significant $25 \%-32 \%$ lower risk of hip fracture, for the highest versus lowest consumption in cohort studies. Unlike milk, yogurt and cheese contain probiotics, which can improve bone formation, increase bone mass density and prevent bone loss. A study by Lei. et al., used probiotics to treat elderly patients with hip fracture on functional recovery [46].

This meta-analysis involved a larger number of cases to enhance the statistical power. Subgroup and doseresponse analyses were performed to explore the heterogeneity of sources, used contour-enhanced funnel plots to display publication bias, and performed sensitivity analyses to test the robustness of the risk estimates. This meta-analysis is the first meta-analysis to evaluate the relationship between different types of dairy product consumption and hip fracture risk.
Our meta-analysis was subject to some limitations that may have affected the results. First, it is possible that the link between dairy product consumption and hip fracture risk could be interpreted within measurement errors in the dietary assessment. Food frequency questionnaires can be limited by errors in reporting and by incomplete assessment of all sources of dairy product consumption, which can lead to misclassification of exposure and weaken the association towards the null. Second, compared to cohort studies, case-control studies may have recall and selection bias. Dairy products and their possible role in bone health were widely discussed. The public debate might produce a bias in collecting dietary data among patients. Due to recall error, or dietary changes after hip fracture, participants are likely to have provided the current dietary data as a proxy for the previous diet. Cases reported a significant decrease in the frequency of dairy product consumption after the hip fracture, and it was even more obvious when the cases that provided a deliberate change in their dietary date were excluded. However, this was not evident with the control participants [47]. Indeed, inconsistent results between cohort and case-control studies were found, which might be explained by publication bias that was detected in the case-control studies. Publication bias refers to the idea that studies with positive results are more likely to be submitted for publication than those with negative results, which leads to misleading conclusions in meta-analyses. Third, differential loss to followup is a well-known source of bias in cohort studies, and the direction of that bias is hard to predict. Identification of fracture events may be an additional reason in cohort studies. Furthermore, the included studies may be limited by their use of differing means of assessing and measuring exposure and outcome, thereby impacting 
Table 4 Subgroup analyses comparing milk intake and hip fracture risk for case-control and cohort studies

\begin{tabular}{|c|c|c|c|c|c|c|c|c|c|c|c|c|}
\hline & \multicolumn{6}{|c|}{ Cohort studies $(n=9)$} & \multicolumn{6}{|c|}{ Case-control studies $(n=7)$} \\
\hline & $n$ & $\mathrm{RR}$ & $95 \% \mathrm{Cl}$ & $P^{2}(\%)$ & $p^{a}$ & $p^{b}$ & $n$ & OR & $95 \% \mathrm{Cl}$ & $P^{2}(\%)$ & $P^{a}$ & $p^{\mathrm{b}}$ \\
\hline \multicolumn{13}{|l|}{ Study quality } \\
\hline Score $\geq 8$ & 4 & 0.98 & $0.75-1.27$ & 90.0 & $<0.01$ & 0.90 & 4 & 0.80 & $0.67-0.95$ & 10.0 & 0.34 & 0.05 \\
\hline Score $<8$ & 4 & 1.03 & $0.86-1.24$ & 0.0 & 0.82 & & 3 & 0.42 & $0.25-0.71$ & 35.0 & 0.21 & \\
\hline \multicolumn{13}{|l|}{ Region } \\
\hline USA & 4 & 1.00 & $0.96-1.03$ & 0.0 & 0.84 & 0.44 & 1 & 1.10 & $0.63-1.94$ & NA & NA & 0.04 \\
\hline Europe & 3 & 0.98 & $0.68-1.41$ & 86.0 & $<0.01$ & & 3 & 0.77 & $0.65-0.90$ & 0.0 & 0.39 & \\
\hline Asia & 1 & 0.54 & $0.26-1.12$ & & & & 3 & 0.42 & $0.25-0.71$ & 35.0 & 0.21 & \\
\hline \multicolumn{13}{|l|}{ Sex } \\
\hline Male & 5 & 0.91 & $0.70-1.19$ & 48.0 & 0.10 & 0.68 & 1 & 0.82 & $0.61-1.11$ & NA & NA & 0.28 \\
\hline Female & 6 & 1.07 & $0.78-1.47$ & 81.0 & $<0.01$ & & 4 & 0.78 & $0.53-1.14$ & 58.0 & 0.07 & \\
\hline Both & 3 & 0.91 & $0.70-1.18$ & 23.8 & 0.23 & & 2 & 0.46 & $0.25-0.85$ & 44.0 & 0.18 & \\
\hline \multicolumn{13}{|l|}{ No. of cases } \\
\hline$\geq 1000$ & 2 & 1.19 & $0.85-1.66$ & 90.0 & $<0.01$ & 0.16 & 1 & 0.71 & $0.58-0.87$ & NA & NA & 0.21 \\
\hline $100-1000$ & 4 & 1.00 & $0.82-1.21$ & 0.0 & 0.57 & & 4 & 0.83 & $0.65-1.06$ & 24.0 & 0.27 & \\
\hline$\leq 100$ & 6 & 0.79 & $0.60-1.04$ & 46.0 & 0.10 & & 2 & 0.28 & $0.15-0.55$ & 0.0 & 0.84 & \\
\hline \multicolumn{13}{|c|}{ Duration of follow-up years } \\
\hline$\geq 10$ years & 5 & 1.02 & $0.84-1.25$ & 86.0 & $<0.01$ & 0.63 & NA & NA & NA & NA & NA & NA \\
\hline$<10$ years & 3 & 0.89 & $0.62-1.29$ & 0.0 & 0.98 & & NA & NA & NA & NA & NA & NA \\
\hline \multicolumn{13}{|l|}{ Age } \\
\hline$\geq 70$ & 4 & 1.00 & $0.96-1.03$ & 0.0 & 0.80 & 0.45 & 3 & 0.61 & $0.34-1.09$ & 68.0 & 0.04 & 0.66 \\
\hline$<70$ & 5 & 0.89 & $0.66-1.02$ & 83.0 & $<0.01$ & & 4 & 0.76 & $0.57-1.01$ & 52.0 & 0.10 & \\
\hline \multicolumn{13}{|c|}{ Adjustment for confounders } \\
\hline \multicolumn{13}{|l|}{ Smoking } \\
\hline Yes & 5 & 1.06 & $0.87-1.29$ & 85.0 & $<0.01$ & 0.21 & 2 & 0.87 & $0.67-1.12$ & 0.0 & 0.50 & 0.32 \\
\hline No & 3 & 0.78 & $0.55-1.11$ & 0.0 & 0.52 & & 5 & 0.60 & $0.42-0.88$ & 60.0 & 0.04 & \\
\hline \multicolumn{13}{|l|}{ Alcohol } \\
\hline Yes & 4 & 1.10 & $0.84-1.43$ & 81.0 & $<0.01$ & 0.18 & 2 & 0.87 & $0.67-1.12$ & 0.0 & 0.50 & 0.32 \\
\hline No & 4 & 0.93 & $0.79-1.10$ & 16.0 & 0.31 & & 5 & 0.60 & $0.42-0.88$ & 60.0 & 0.04 & \\
\hline \multicolumn{13}{|l|}{ BMI } \\
\hline Yes & 5 & 1.00 & $0.77-1.29$ & 79.0 & $<0.01$ & 0.71 & 4 & 0.80 & $0.67-0.95$ & 10.0 & 0.34 & 0.05 \\
\hline No & 3 & 0.99 & $0.96-1.03$ & 0.0 & 0.83 & & 3 & 0.42 & $0.25-0.71$ & 35.0 & 0.21 & \\
\hline \multicolumn{13}{|c|}{ Physical activity } \\
\hline Yes & 6 & 1.03 & $0.82-1.29$ & 75.0 & $<0.01$ & 0.47 & 2 & 0.72 & $0.52-1.00$ & 37.0 & 0.21 & 0.93 \\
\hline No & 2 & 0.82 & $0.47-1.43$ & 63.0 & 0.10 & & 5 & 0.67 & $0.45-1.01$ & 65.0 & 0.02 & \\
\hline \multicolumn{13}{|c|}{ Sunlight exposure } \\
\hline Yes & 0 & NA & NA & NA & NA & NA & 2 & 0.74 & $0.63-0.88$ & 0.0 & 0.43 & 0.67 \\
\hline No & 8 & 1.01 & $0.84-1.20$ & 80.0 & $<0.01$ & & 5 & 0.62 & $0.38-1.01$ & 67.0 & 0.02 & \\
\hline \multicolumn{13}{|c|}{ Total energy intake } \\
\hline Yes & 5 & 1.11 & $0.91-1.35$ & 86.0 & $<0.01$ & 0.05 & 0 & NA & NA & NA & NA & NA \\
\hline No & 3 & 0.69 & $0.49-0.96$ & 0.0 & 0.45 & & 7 & 0.71 & $0.55-0.91$ & 54.0 & 0.04 & \\
\hline \multicolumn{13}{|c|}{ Calcium and vitamin D supplementation } \\
\hline Yes & 5 & 1.12 & $0.92-1.36$ & 86.0 & $<0.01$ & 0.04 & 0 & NA & NA & NA & NA & NA \\
\hline No & 3 & 0.69 & $0.50-0.95$ & 0.0 & 0.47 & & 7 & 0.71 & $0.55-0.91$ & 54.0 & 0.04 & \\
\hline
\end{tabular}




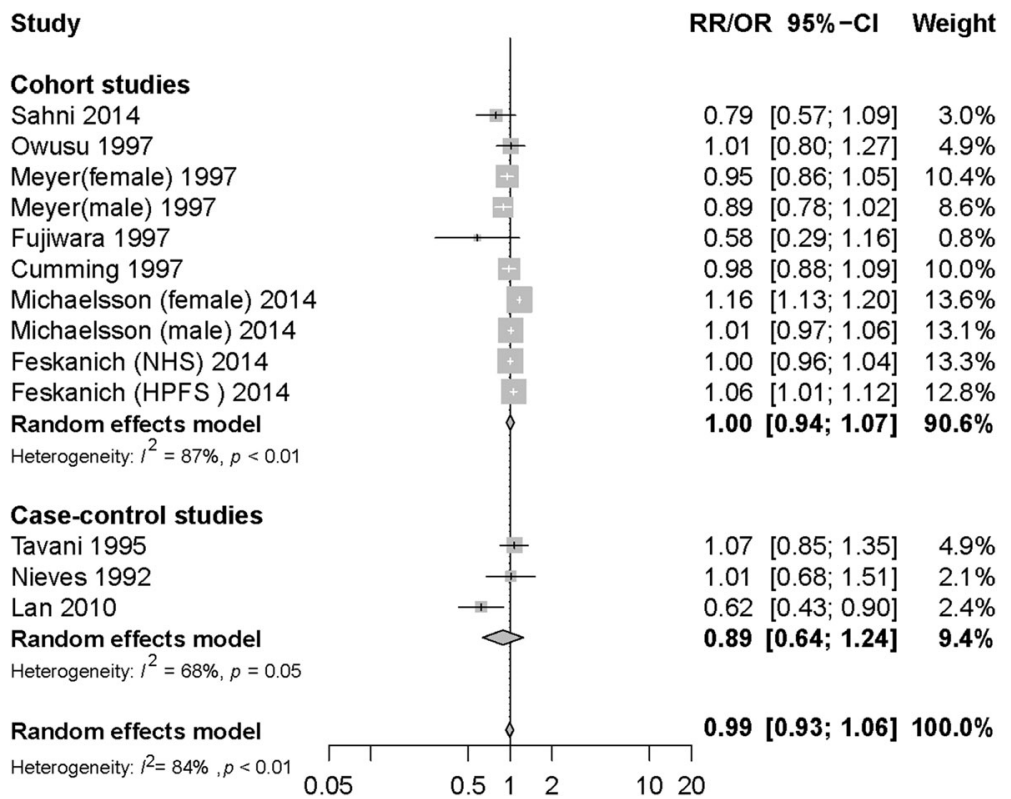

Fig. 4 Milk consumption and risk of hip fracture. The summary relative risk per $200 \mathrm{~g} / \mathrm{d}$ by using random-effects models

study quality scores. Ascertainment of hip fractures was partly or completely assumed by self-report in the included studies, which is also a source of bias. Mortality after hip fracture is high and a large proportion of persons who suffer a hip fracture are discharged to nursing

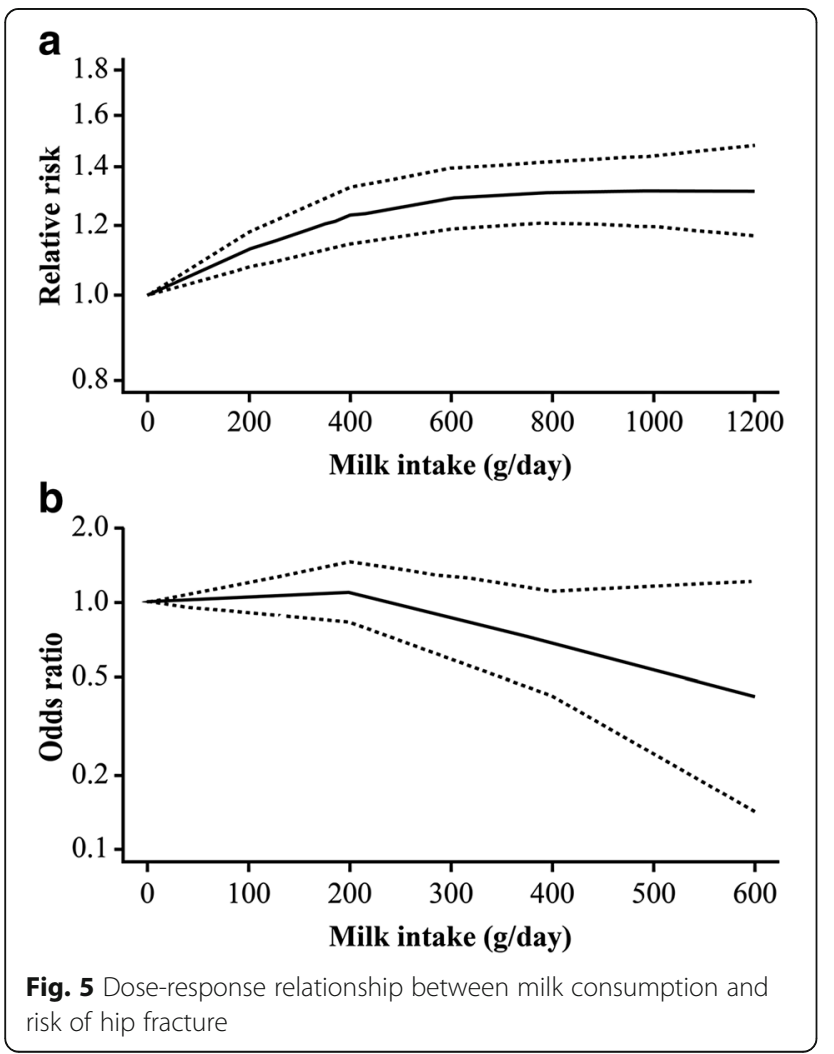

facilities. Loss to follow-up and self-report are two important factors that increase the probability of a hip fracture not being reported, which could have affected the results. Fourth, high heterogeneity across studies was observed in this meta-analysis and baseline characteristics and adjustment for confounders also affected the results. Analyses of high versus low consumption were limited because of the different units (glasses/day, times/ week, gram/day, servings/week) of dairy product consumption reported between studies, which may explain some heterogeneity in the results. Meta-regression analyses were used to explore potential sources of heterogeneity in our meta-analysis results, such as whether the studies adjusted for calcium and vitamin D supplementation, BMI, total energy intake, region, and study quality. Energy intake may increase when dairy product consumption increases, and BMI increases as total energy intake increases [48]. Several previous meta-analyses have suggested that BMI is inversely associated with hip fracture risk [49-51]. Meanwhile, a recent large, prospective, populationbased study indicated that participants with $\mathrm{BMI} \geq$ $25 \mathrm{~kg} / \mathrm{m}^{2}$ had a reduced risk of hip fracture and patients with $\mathrm{BMI}<22 \mathrm{~kg} / \mathrm{m}^{2}$ had an increased risk compared with those with BMI between 22 and $24.9 \mathrm{~kg} / \mathrm{m}^{2}$ [52], these sources of heterogeneity may have substantially influenced the results. Finally, only a small number of studies were available for the effects of total dairy products, cheese, yogurt, and cream consumption on hip fracture risk. Therefore, there was limited statistical power in the subgroup and dose-response analyses for our meta-analysis. 


\section{Conclusions}

The conclusions of this meta-analysis were discordant. Milk consumption was found to be associated with an average $29 \%$ decrease in hip fracture risk in the included case-control studies. Meanwhile, recall bias or other possible bias could be a major influence on the findings in the case-control studies. The inconsistent findings for cohort studies indicate that there is no consistent evidence on the association between milk consumption and the risk of hip fracture. Therefore, we were unable to draw any conclusion from the estimates on the association between milk consumption and hip fracture risk. Consumption of other dairy products, yogurt and cheese intake was associated with lower risk of hip fracture in cohort studies, and total dairy products and cream was not significantly associated with hip fracture risk.

\section{Additional files}

Additional file 1: Description: Search Phrases for a) PubMed, and b) EMBASE. (DOC $37 \mathrm{~kb}$ )

Additional file 2: Title: Selection procedure for inclusion and exclusion of the studies. (DOC $50 \mathrm{~kb}$ )

\section{Abbreviations}

BMI: Body mass index; Cl: Confidence interval; FFQ: food frequency questionnaire; OR: odds ratio; RR: relative risk; the ICD-10: International Classification of Diseases, 10th revision

\section{Acknowledgements}

We express our appreciation to all of the study participants. This study was supported by the National Natural Science Foundation of China (grant nos. 81702110).

\section{Funding}

This study was supported by the National Natural Science Foundation of China (grant nos. 81702110).

\section{Availability of data and materials}

The data that support the findings of this study are available from the corresponding author upon request.

\section{Author contributions}

$\mathrm{SB}$ and $\mathrm{JH}$ conceived the study design $\mathrm{SB}$ and $\mathrm{JH}$ wrote and applied this protocol under the guidance of JM, SB, JH, YW, KZ, and MY collected data. $\mathrm{SB}$ and $\mathrm{JH}$ drafted the manuscript; $\mathrm{SB}, \mathrm{JH}$ and J.M. contributed to the interpretation of results and subsequent revisions. J.M. revised the study data for inclusion and the manuscript for intellectual content. The final version of the manuscript was approved by all of the authors.

\section{Ethics approval and consent to participate}

Not applicable.

\section{Consent for publication}

Not applicable.

\section{Competing interests}

The authors declare that they have no competing interests.

\section{Publisher's Note}

Springer Nature remains neutral with regard to jurisdictional claims in published maps and institutional affiliations.

\section{Author details}

'Department of Nutrition, the Second Hospital of Tianjin Medical University, No. 23 Pingjiang Road, Tianjin 300211, China. 'Department of Orthopedics, the Second Hospital of Tianjin Medical University, No. 23 Pingjiang Road, Tianjin 300211, China. ${ }^{3}$ Health Examination Centre, the Second Hospital of Tianjin Medical University, No. 23 Pingjiang Road, Tianjin 300211, China.

Received: 20 July 2017 Accepted: 5 January 2018

Published online: 22 January 2018

\section{References}

1. Lotters FJ, Lenoir-Wijnkoop I, Fardellone P, Rizzoli R, Rocher E, Poley MJ. Dairy foods and osteoporosis: an example of assessing the health-economic impact of food products. Osteoporos Int. 2013;24:139-50.

2. Gullberg B, Johnell $O$, Kanis JA. World-wide projections for hip fracture. Osteoporos Int. 1997;7(5):407-13.

3. Cooper C, Campion G, Melton LJ 3rd. Hip fractures in the elderly: a worldwide projection. Osteoporos Int. 1992;2(6):285-9.

4. United Nations, Department of Economic and Social Affairs, Population Division (2013). WorldPopulation Ageing 2013. [Online]. Available: http:// www.un.org/en/development/desa/population/publications/pdf/ageing/ WorldPopulationAgeing2013.pdf. Accessed 1 July 2017.

5. Cummings SR, Melton LJ. Epidemiology and outcomes of osteoporotic fractures. Lancet. 2002:359(9319):1761-7.

6. Nilson F, Moniruzzaman S, Andersson RA. Comparison of hip fracture incidence rates among elderly in Sweden by latitude and sunlight exposure. Scand J Public Health. 2014;42(2):201-6.

7. Hoidrup S, Gronbaek M, Gottschau A, Lauritzen JB, Schroll M. Alcohol intake, beverage preference, and risk of hip fracture in men and women. Copenhagen Centre for Prospective Population Studies. Am J Epidemiol. 1999;149(11):993-1001.

8. Wu ZJ, Zhao P, Liu B, Yuan ZC. Effect of Cigarette Smoking on Risk of Hip Fracture in Men: A Meta-Analysis of 14 Prospective Cohort Studies. PLoS One. 2016;11(12):e0168990

9. Body JJ, Bergmann P, Boonen S, Boutsen Y, Bruyere O, Devogelaer JP, et al. Non-pharmacological management of osteoporosis: a consensus of the Belgian bone Club. Osteoporos Int. 2011;22(11):2769-88.

10. Tucker KL. Osteoporosis prevention and nutrition. Curr Osteoporos Rep. 2009:7(4):111-7.

11. Heaney RP. Calcium, dairy products and osteoporosis. J Am Coll Nutr. 2000; 19(2 Suppl):83S-99S.

12. Sahni S, Mangano KM, Tucker KL, Kiel DP, Casey VA, Hannan MT. Protective association of milk intake on the risk of hip fracture: results from the Framingham original cohort. J Bone Miner Res. 2014;29:1756-62.

13. Michaelsson K, Wolk A, Langenskiold S, Basu S, Warensjo Lemming E, Melhus $\mathrm{H}$, et al. Milk intake and risk of mortality and fractures in women and men: cohort studies. BMJ. 2014;349:g6015.

14. Bischoff-Ferrari HA, Dawson-Hughes B, Baron JA, Kanis JA, Orav EJ, Staehelin $H B$, et al. Milk intake and risk of hip fracture in men and women: a metaanalysis of prospective cohort studies. J Bone Miner Res. 2011;26(4):833-9.

15. Kanis JA, Johansson H, Oden A, De Laet C, Johnell O, Eisman JA, et al. A meta-analysis of milk intake and fracture risk: low utility for case finding. Osteoporos Int. 2005;16(7):799-804.

16. Cumming RG, Cummings SR, Nevitt MC, Scott J, Ensrud KE, Vogt TM, et al Calcium intake and fracture risk: results from the study of osteoporotic fractures. Am J Epidemiol. 1997;145(10):926-34.

17. Food Standards Agency. Food portion sizes, third edition. London: TSO; 2003. [Online]. Available: https://www.food.gov.uk/sites/default/files/ research-report-ao1020.pdf. Accessed 1 July 2017.

18. Wiseman M. The second World Cancer Research Fund/American Institute for Cancer Research expert report. Food, nutrition, physical activity, and the prevention of cancer: a global perspective. Proc Nutr Soc. 2008;67(3):253-6.

19. Soedamah-Muthu SS, Ding EL, Al-Delaimy WK, FB H, Engberink MF, Willett WC, et al. Milk and dairy consumption and incidence of cardiovascular diseases and all-cause mortality: dose-response meta-analysis of prospective cohort studies. Am J Clin Nutr. 2011;93(1):158-71.

20. Aune D, Navarro Rosenblatt DA, Chan DS, Vieira AR, Vieira R, Greenwood $D C$, et al. Dairy products, calcium, and prostate cancer risk: a systematic review and meta-analysis of cohort studies. Am J Clin Nutr. 2015;101(1): 87-117. 
21. US Department of Agriculture, Agricultural Research Service. USDA National Nutrient Database for Standard Reference. 2015.

22. Wells G, Shea B, O'connell D, Peterson J, Welch V, Losos M, et al. The Newcastle-Ottawa scale (NOS) for assessing the quality of nonrandomised studies in meta-analyses; 2000. [Online]. Available: https://www.ohri.ca/ programs/clinical_epidemiology/oxford.htm. Accessed 1 July 2017.

23. DerSimonian R, Laird N. Meta-analysis in clinical trials. Control Clin Trials. 1986;7(3):177-88.

24. Greenland S, Longnecker MP. Methods for trend estimation from summarized dose-response data, with applications to meta-analysis. Am J Epidemiol. 1992;135(11):1301-9.

25. Higgins JP, Thompson SG, Deeks JJ, Altman DG. Measuring inconsistency in meta-analyses. BMJ. 2003;327(7414):557-60.

26. Egger M, Davey Smith G, Schneider M, Minder C. Bias in meta-analysis detected by a simple, graphical test. BMJ. 1997:315(7109):629-34.

27. Begg CB, Mazumdar M. Operating characteristics of a rank correlation test for publication bias. Biometrics. 1994:50(4):1088-101.

28. Duval S, Tweedie R. Trim and fill: a simple funnel-plot-based method of testing and adjusting for publication bias in meta-analysis. Biometrics. 2000; 56(2):455-63.

29. Jha RM, Mithal A, Malhotra N, Brown EM. Pilot case-control investigation of risk factors for hip fractures in the urban Indian population. BMC Musculoskelet Disord. 2010;11:49.

30. Lan TY, Hou SM, Chen CY, Chang WC, Lin J, Lin CC, et al. Risk factors for hip fracture in older adults: a case-control study in Taiwan. Osteoporos Int. 2010;21(5):773-84.

31. Jitapunkul S, Yuktananandana P, Parkpian V. Risk factors of hip fracture among Thai female patients. J Med Assoc Thail. 2001;84(11):1576-81.

32. Johnell O, Gullberg B, Kanis JA, Allander E, Elffors L, Dequeker J, et al. Risk factors for hip fracture in european women: the MEDOS study. J Bone Miner Res. 1995;10(11):1802-15

33. Feskanich D, Bischoff-Ferrari HA, Frazier AL, Willett WC. Milk consumption during teenage years and risk of hip fractures in older adults. JAMA Pediatr. 2014;168(1):54-60.

34. Fujiwara S, Kasagi F, Yamada M, Kodama K. Risk factors for hip fracture in a Japanese cohort. J Bone Miner Res. 1997;12(7):998-1004.

35. Benetou V, Orfanos P, Zylis D, Sieri S, Contiero P, Tumino R, et al. Diet and hip fractures among elderly Europeans in the EPIC cohort. Eur J Clin Nutr. 2011;65(1):132-9.

36. Feart C, Lorrain S, Ginder Coupez V, Samieri C, Letenneur L, Paineau D, et al. Adherence to a Mediterranean diet and risk of fractures in French older persons. Osteoporos Int. 2013;24(12):3031-41.

37. Owusu W, Willett WC, Feskanich D, Ascherio A, Spiegelman D, Colditz GA. Calcium intake and the incidence of forearm and hip fractures among men. J Nutr. 1997;127(9):1782-7.

38. Kanis J, Johnell O, Gullberg B, Allander E, Elffors L, Ranstam J, et al. Risk factors for hip fracture in men from southern Europe: the MEDOS study. Mediterranean osteoporosis study. Osteoporos Int. 1999;9(1):45-54.

39. Tavani A, Negri E, La Vecchia C. Calcium, dairy products, and the risk of hip fracture in women in northern Italy. Epidemiology. 1995;6(5):554-7.

40. Cumming RG, Klineberg RJ. Case-control study of risk factors for hip fractures in the elderly. Am J Epidemiol. 1994;139(5):493-503.

41. Nieves JW, Grisso JA, Kelsey JLA. Case-control study of hip fracture: evaluation of selected dietary variables and teenage physical activity. Osteoporos Int. 1992:2(3):122-7.

42. Meyer HE, Pedersen Jl, Løken EB, Tverdal A. Dietary factors and the incidence of hip fracture in middle-aged Norwegians: a prospective study. Am J Epidemiol. 1997;145(2):117-23.

43. Bonjour JP, Lecerf JM. Dairy micronutrients: new insights and health benefits. Introduction J Am Coll Nutr. 2011;30(5 Suppl 1):399S

44. Bolland MJ, Grey A. A case study of discordant overlapping meta-analyses: vitamin D supplements and fracture. PLoS One. 2014;9(12):e115934.

45. Chapuy MC, Arlot ME, Duboeuf F, Brun J, Crouzet B, Arnaud S, Delmas PD, Meunier PJ. Vitamin D3 and calcium to prevent hip fractures in elderly women. N Engl J Med. 1992;327(23):1637-42.

46. Lei $M$, Hua LM, Wang DW. The effect of probiotic treatment on elderly patients with distal radius fracture: a prospective double-blind, placebocontrolled randomised clinical trial. Benef Microbes. 2016;7(5):631-7.

47. Michaelsson K, Holmberg L, Ljunghall S, Mallmin H, Persson PG, Wolk A. Effect of prefracture versus postfracture dietary assessment on hip fracture risk estimates. Int J Epidemiol. 1996;25(2):403-10.
48. Yoshita K, Arai Y, Nozue M, Komatsu K, Ohnishi H, Saitoh S, et al. Total energy intake and intake of three major nutrients by body mass index in Japan: NIPPON DATA80 and NIPPON DATA90. Am J Epidemiol. 2010; 20(Suppl 3):S515-23.

49. Leslie WD, Orwoll ES, Nielson CM, Morin SN, Majumdar SR, Johansson H, et al. Estimated lean mass and fat mass differentially affect femoral bone density and strength index but are not FRAX independent risk factors for fracture. J Bone Miner Res. 2014;29(11):2511-9.

50. De Laet C, Kanis JA, Oden A, Johanson H, Johnell O, Delmas P, et al. Body mass index as a predictor of fracture risk: a meta-analysis. Osteoporos Int. 2005;16(11):1330-8

51. Tang X, Liu G, Kang J, Hou Y, Jiang F, Yuan W, et al. Obesity and risk of hip fracture in adults: a meta-analysis of prospective cohort studies. PLoS One. 2013;8(4):e55077.

52. Sogaard AJ, Holvik K, Omsland TK, Tell GS, Dahl C, Schei B, et al. Age and sex differences in body mass index as a predictor of hip fracture: a NOREPOS study. Am J Epidemiol. 2016;184(7):510-9.

\section{Submit your next manuscript to BioMed Central and we will help you at every step:}

- We accept pre-submission inquiries

- Our selector tool helps you to find the most relevant journal

- We provide round the clock customer support

- Convenient online submission

- Thorough peer review

- Inclusion in PubMed and all major indexing services

- Maximum visibility for your research

Submit your manuscript at www.biomedcentral.com/submit
) Biomed Central 